
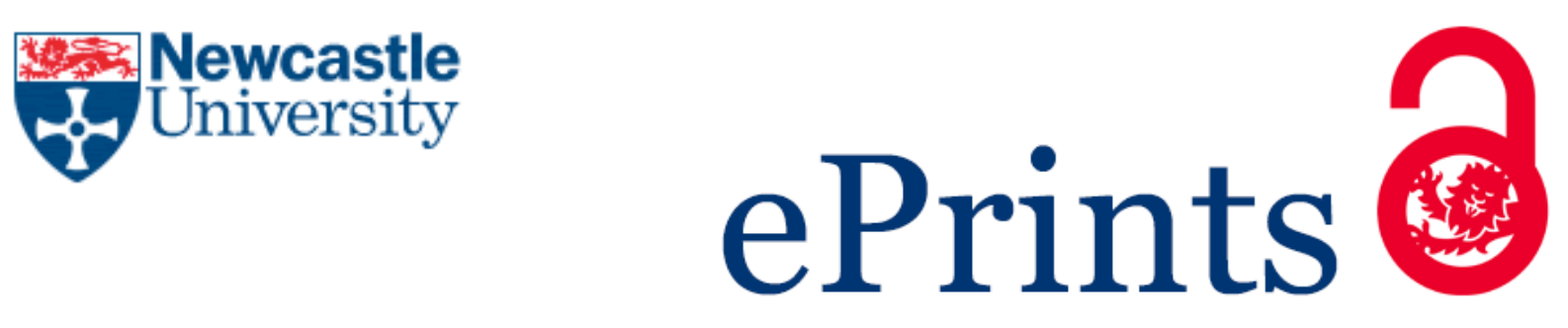

Shaw R. Bringing Deleuze and Guattari down to Earth through Gregory Bateson: Plateaus, Rhizomes and Ecosophical Subjectivity. Theory, Culture and Society 2015, 32(7-8), 151-171.

\title{
Copyright:
}

C 2015 the author.

DoI link to article:

http://dx.doi.org/10.1177/0263276414524451

Date deposited:

$03 / 12 / 2015$

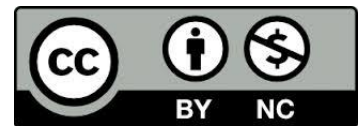

This work is licensed under a Creative Commons Attribution-NonCommercial 3.0 Unported License 
Bringing Deleuze and Guattari down to Earth through Gregory Bateson: Plateaus, Rhizomes and

\title{
Ecosophical Subjectivity
}

\begin{abstract}
While Deleuze and Guattari described themselves as 'geophilosophers', researchers are just beginning to explore the influences on their writing which lead them to this conclusion. Gregory Bateson, who is dismissed by Deleuze and Guattari as living "une carrière à l'américaine", contributed to the development of several concepts which Deleuze and Guattari later used to build up their vision of the relationship between earth and subjectivity. Perhaps because of their dismissal of him, there have been few attempts to construct a Batesonian reading of Deleuze and Guattari. This paper begins to offer two central ways in which we might do this. First, it explores the concepts which moved from Bateson to the two-volumes of Capitalism and Schizophrenia. In doing so, Bateson is used to develop an understanding of Capitalism and Schizophrenia as an attempt to create new non-schismogenic formats of social relation. Here, the earth is a necessary 'grounding' for plateaus. Second, this paper then builds on this through Guattari's concept of ecosophical subjectivity, arguing that through further engagement with Bateson, Guattari builds up what he refers to as the 'ethico-political' dimensions of his work. It concludes with the claim that as a key influence on several elements of their work, exploring Bateson in relation to Deleuze and Guattari can open up new understandings of their ideas, particularly with regards to the forms of 'earthliness' that they develop.
\end{abstract}




\section{Bringing Deleuze and Guattari down to Earth through Gregory Bateson: Plateaus, Rhizomes and Ecosophical Subjectivity:}

\section{Introduction}

"The scientist as such has no revolutionary potential; he is the first integrated agent of integration, a refuse for bad conscience, and the forced destroyer of his own creativity. Let us consider the more striking [than André Grosz] example of a carrière à l'américaine, with abrupt mutations, just as we imagine such a career to be: Gregory Bateson begins by fleeing the civilized world, by becoming an ethnologist and following the primitive codes and the savage flows; then he turns in the direction of flows that are more and more decoded, those of schizophrenia, from which he extracts an interesting psychoanalytic theory; then, still in search of a beyond, of another wall to break through, he turns to dolphins, to the language of dolphins, to flows are that are even stranger and more deterritorialised. But where does the dolphin flux end, if not with the basic research projects of the American army, which brings us back to preparations for war and to the absorption of surplus value" (Deleuze \& Guattari, 1983:257).

Aside from four other brief mentions, (Deleuze \& Guattari, $1983: 88,394 ; 1987: 28,197$ ) the above is the entirety of the discussion of the work of Gregory Bateson that takes place across the two volumes of Capitalism and Schizophrenia. Its message seems straight forward. For Deleuze and Guattari, Bateson is the failed-revolutionary: the (social) scientist who followed deterritorialised lines of flight which led him straight back into the war-machine. He is presented as something of a curiosity, a footnote, an interesting tale of a carrière à l'américaine, but nothing more. Deleuze and Guattari's criticism, however, belies the depth of influence that Bateson had on their work, both in its co-authored form and perhaps most strikingly in the latter years of Guattari's single authored work. Concepts such as plateaus (G. Bateson, 1973:113; Deleuze \& Guattari, 1987), rhizome (G. 
Bateson, 1958:249; Deleuze \& Guattari, 1984:10), the double bind (G. Bateson, 1973:271; Deleuze \& Guattari, 1983:79), ecosophical thought (G. Bateson, 1973:496; Guattari, 2000:33) and schizoanalysis (G. Bateson, 1973:339; Guattari, 1998) all appear to have their origins, at least in part, in the work of Bateson.

This article has two aims. First, it offers a general discussion focusing on those topics which travel between the work of Bateson and Deleuze and Guattari. My claim is that Bateson was not just a productive source of concepts, but was also an important influence on the pair's writing. While the concepts discussed in this article have clearly been developed out of multiple sources - each concept themselves forming diverse rhizomes - Bateson's influence goes beyond simply providing names for ideas. While this necessitates an initially broad and generalized discussion, it also helps redress the absence of significant exploration of this relationship to date. This goes some way to correcting the currently small secondary literature on Bateson in relation to Deleuze and Guattari.

Second and developing this, the article then focuses more closely on Bateson's contribution to the 'geo-'philosophy of Deleuze and Guattari, and particularly Guattari. From the topography of plateaus to the earthly rhizomes, many of the concepts that move from Bateson to Deleuze and Guattari are those that ground them in the earth. Moreover, the earthliness of these concepts is not frivolous wordplay. Rather, Deleuze and Guattari were involved in a self-identified 'geophilosophical' project entailing "thinking earth, ground, land and territory" (Bonta \& Protevi, 2004:9). It is here that the importance of developing a reading of Deleuze and Guattari through Bateson becomes apparent: while the 'earthliness' of Deleuze and Guattari has been explored before, the ecosophical component of this earthliness that Guattari later develops is less well studied (Genosko, 2000; Guattari, 2000). The 'ecosophical subject' offers an important vision of the actual and possible relationship between humanity and earth (Schroeder, 2012). As Clark argues, "struggles over geosocial formations - however they unfold - are emerging as the foremost political and socio-material challenge of our times." (Clark, 2013). Multiple academics from across disciplines have in recent 
years called for ways of rethinking earth and subjectivity (Latour, 2007; Protevi, 2013; Sloterdijk, 2009; Zalasiewicz, Williams, Haywood, \& Ellis, 2011). Through what Guattari calls the 'ethicopolitical' articulation of ecosophy (Guattari, 2000), this reading can help open up new ways of living which avoid what Bateson refers to as the 'pathology' of contemporary subjectivities and subsequent ecological crisis (G. Bateson, 1973; G. Chesters \& Welsh, 2006).

\title{
"Une carrière à l’américaine"? Bateson, Deleuze and Guattari
}

\begin{abstract}
"I am sure that there are people here who know every field of knowledge that I have touched much better than I know it. It is true that I have touched a number of fields, and I can probably face any one of you and say I have touched a field that you have not touched. But I am sure that for every field I have touched, there are people here who are more expert than I. I am not a very well-read philosopher, and philosophy is not my business. I am not a very well-read anthropologist, and anthropology is not exactly my business" (Bateson 1973:454).
\end{abstract}

Bateson was unusual in the breadth of his interests, closer to a nineteenth century polymath than to the specialized researchers associated with contemporary academia. Though he initially gained renowned as an anthropologist working in Bali alongside his partner Margaret Mead (G. Bateson \& Mead, 1942), he maintained throughout his career an active research interest in a number of fields. The mathematical philosophy of Bertrand Russell was a major influence on Bateson's early thought (see Russell, 1903), and this would later shape Bateson's interest in groups and sets. During World War Two, Bateson moved away from ethnographic anthropology onto a variety of projects working with the American military, exploring the nexus between anthropological theory, communication theory and biochemistry in order to design propaganda materials. This helped move Bateson towards clinical psychiatry in the 1950s, in which he mixed an anthropological sensibility with scientific experimentation to explore the conditions from which illnesses such as schizophrenia could emerge. Bateson became a major figure in the growing field of cybernetics (Schwartzman, 1978), 
thanks to his work in attempting to understand the nature of communication and information (G. Bateson, 1951, 1968). In particular, he began to reconceive the concept of 'mind' not as a trait of human beings or a knowing subject, but as immanent to systems of information exchange. As his biographer Lipset explains, "coral reefs, redwood forests, and human societies [for Bateson] all displayed the attributes of mind"(Lipset, 1980:273). Any complex system displays attributes of mind, so that where mind exists no single part has unilateral control over the whole (Bateson, 1973:316). Thus the notion that the self rests in the body of a human and can either act alone, or as master over its environment- that ' $l$ ' can do anything in a meaningful way - is, for Bateson, a 'pathology of epistemology' (G. Bateson, 1973). This pathological epistemology causes us to overlook our connections to the broader environment, threatening the very existence of humanity and causing the ecological crisis.

In 1973, the disparate body of work that Bateson had undertaken was collected together in a book which was titled Steps to an Ecology of Mind (hereafter: 'Steps'). Prior to this, Bateson had often given "the impression, even to his strongest admirers, of taking up and then abandoning a series of different disciplines" (M.C. M. C. Bateson, 1999:viii): Lipset describes Bateson as having previously been 'the invisible scientist' (Lipset, 1980), working on multiple projects but rarely staying in an area for very long. In Steps, a new coherence to Bateson's work appears, in which he introduces his life's research as proposing "a new way of thinking about ideas and about those aggregates of ideas which I call 'minds'" (G. Bateson, 1973:xxiii). Indeed, this coherence for Bateson only appeared later in his life, meaning that his identification of his previous work as 'steps' towards his an ecology of mind is a retroactive narrative, covering a slow development in his thought from 1935 (the earliest work which is included in Steps) through to 1971. In Bateson's later life, before his death in 1980, he continued to develop his work philosophically, bringing in ideas from eastern philosophy to try and explore what he saw as the increasingly conflicting relationship between human society and environment (G. Bateson, 1979; G. Bateson \& Bateson, 1987). Bateson's work can thus be characterized as seeking connections between behavioral sciences, anthropology, psychiatry, 
cybernetics and biology, in order to explore the relationship between selves and the world. His influential conclusion is that, as Guattari paraphrases, "nature cannot be separated from culture; in order to comprehend the interactions between ecosystems, the mechanosphere and the social and individual Universes of reference, we must learn to think "transversally" (Guattari, 2000:29). The self does not exist independently of the environment: both concepts emerge only from a pathological epistemology (G. Bateson, 1973:486). Rather, the unit of experience is "organism plus environment", to which mind, or the subject, is immanent.

Much of the existing literature on Deleuze and Guattari pays little attention to Bateson. Massumi makes just one reference to Bateson in his 'Users Guide to Capitalism and Schizophrenia' (Massumi, 1992:7), while Genosko does not mention Bateson at all in his companion essay to Guattari's The Three Ecologies (Genosko, 2000), despite Guattari opening the essay with a quote from Bateson (Guattari, 2000:19). This replicates the treatment that Deleuze and Guattari themselves afford Bateson: the odd-reference here, the use of a term or concept there, but no sustained engagement or exploration. Exceptions to this include the work of Chesters and Welsh, who draw from Bateson's work, and the further development of key concepts such as the frame by Goffman, as a way of connecting Deleuze and Guattari into complexity theory (G. Chesters \& Welsh, 2006). They also build on the concepts of rhizomes and plateaux [sic], in order to try and better capture potential political formations for the 'multitude' (Chesters \& Welsh, 2005; 2006). A review of the two volumes of Capitalism and Schizophrenia by Samuel is probably the most extensive attempt to consider the broader influence that Bateson has had on Deleuze and Guattari (Samuel, 2002). Here, Bateson is conceived as a "major precursor" in shifting from a psychological concept of the self to an eco-social concept of the self. For Samuel, "Deleuze and Guattari agree with Bateson in rejecting the conventional human subject, but they are equally opposed to dissolving the subject into a mere exchange of information" (Samuel, 2002:423). As such it is the cybernetics of Bateson, and the replacement of psyche and body with systems of information which causes the break with Deleuze and Guattari. Samuel's review takes Bateson as a case study of the relationship between Deleuze 
and Guattari and social scientists, opening the path for a fuller exploration of Bateson's influence on their work. Beyond these examples, the literature on Bateson in relation to Deleuze and Guattari is limited to occasional discussions of the of rhizome (Bell, 2006), or of the connection between Guattari and Bateson's versions of ecological/ecosophical epistemologies (Goodburn, 2010; Taffel, 2012). Thus the first aim of this paper is to set out in more detail this relationship, focusing on the concepts used in Deleuze and Guattari's two-volume Capitalism and Schizophrenia.

\section{Batesonian Traces in Capitalism and Schizophrenia}

Bateson is of course just one of the many, varied influences on the most influential and heterogeneous of the collaborations between Deleuze and Guattari, Capitalism and Schizophrenia. Deleuze is quite clear how he views his use of other writers' concepts: he sees them as "monstrous children" (Deleuze, 1973), in which the idea developed by Deleuze and Guattari are radically altered from their original sources. As such, it would be wrong to claim that concepts which travel from Bateson (or any source) to Deleuze and Guattari stay the same as they move. Nevertheless, Deleuze's quote also reveals that the radically new concepts are still clearly descended from the ideas which parented them: Deleuze and Guattari did more than simply borrow convenient words for their own concepts. Bateson's phrases and ideas can be found throughout much of Deleuze and Guattari's collaborative work, particularly in Capitalism and Schizophrenia. Contrary to those who have identified the rhizome as his central contribution to Deleuze and Guattari (Bell, 2006), I argue that it is the earthly and territorial concept of the plateau which most shaped their work. It seems appropriate, then, to begin to explore the history of the concept of the plateau and why Bateson's rendering of it made it an appropriate 'solution' for Deleuze and Guattari to draw upon in the second of the two volumes of Capitalism and Schizophrenia.

For both Bateson and Deleuze and Guattari, a 'plateau of intensity' was an answer to a problem; or, rather than an answer, a solution which sought to displace and deproblematize a problem. Bateson claims that social conflicts tend to build to a point of release: what he calls 'schismogenesis', that is, 
the creation and emergence of schisms between groups (G. Bateson, 1973). The resultant violent resolution is usually followed by periods of relative stability and calm, within which further schismogenesis occurs. For Bateson, writing in the 1930s, this problem was particularly pertinent. He saw that at that moment, "the nations Europe are far advanced in symmetrical schismogenesis and are ready to fly at each other's throats; while within each nation are to be observed growing hostilities between the various social strata, symptoms of complementary schismogenesis" (G. Bateson, 1973:70). In facing this problem, Bateson was attempting to face the problem of growing international, inter-ethnic and inter-class conflicts in Europe, and to imagine situations in which war could be avoided as an outcome. It is worth remembering that much of Deleuze and Guattari's work is also framed as an attempt to avoid the repetition of the growth of fascism in this period of conflict (Deleuze \& Guattari, 1987). As well as in the context of inter-group hostilities, Bateson also used schismogenesis to describe the build-up towards sexual release, and to describe the development of confusion and tension in a schizophrenic prior to the release of a schizophrenic episode (G. Bateson, 1958). In other words, schismogenesis is any sort of build-up of mutually conflicting processes which can result in a violent resolution. For Bateson, such schismogenesis was problematic because of the damage often associated with a schismogenic episode in a social, psychological or political setting.

In his research with Mead in Bali, Bateson hoped that he might have found the answer to the problem with schismogenesis: a society with no "schismogenic sequences" (G. Bateson, 1973:112). Rather, Balinese society was characterised by "continual nonprogressive change" (G. Bateson, 1973:125), in which conflict was not expressed through the schismogenesis, but through constant becomings which produce a steady state. In other words, in place of this conflict or expression of release, the Balinese "substitute a plateau of intensity that is maintained and stabilized without release" (Bell, 2006:99). We might ask questions about this research - as Rahn notes, the characterization of a 'tribal' culture as having 'the answer' for Western problems repeats a problematic anthropological imagination (Rahn, 2008). While this research does seem to repeat this discourse, it also played an important role for Bateson in developing his thought about 
schismogenesis as a problem, and the plateau as a potential way out. Schismogenesis is avoided via constant maintenance of plateaus of intensity in which neither normality nor neurosis, neither structure nor crisis, are the goal. Rather, the plateau of intensity is a goal-in-itself, a situation of constant evolution and becoming in which conflict does not build, but is expressed and released. Conflict and pleasure are thus maintained together, in complex 'rhizomes'.

Deleuze and Guattari's plateaus directly descend from Bateson (Chesters and Welsh, 2006), with an aim of overcoming the Oedipal need for climax. Like Bateson, they see problems of the schizophrenic, the war-machine and the Oedipal complex as all reflections of similar schismogenic processes. Therefore, in the second volume of Capitalism and Schizophrenia, Deleuze and Guattari set out to write and create a number of these plateaus of intensity (Deleuze \& Guattari, 1987:24), in order to seek new vocabularies for overcoming schismogenesis. This is one of the few occasions where they acknowledge their debt to Bateson: they take on directly his understanding of plateaus as "a continuous self-vibrating region of intensities whose development avoids any orientation toward a culmination point or external end" (Deleuze \& Guattari, 1987:24). The geography of the plateau is worth noting here. It is a 'self-vibrating region': a connected set of moments and experiences which are nonetheless able to move themselves and each other. The territorialization (Deleuze \& Guattari, 1987) into region is what holds the plateau together. The challenge of the plateau is to generate a field which is sufficiently connected to form region, while sufficiently lose to allow for self-vibration. The earth thus takes on a grounding role: it is necessary for the plateau to be held together.

The rhizome enters as a way of ensuring that the 'geo-' required for the plateau is held together. For Bateson, the rhizome is a tentative description of a non-schismogenic community which constantly divides "like rhizome of a lotus"(G. Bateson, 1958:249). Crucially, then, these plateaus allow the rhizome to be "always in the middle, between things, [in]... the conjunction" (Deleuze \& Guattari, 1987:27). Rhizomes are thus the ever braiding, sinuous paths which avoid the peaks and troughs of 
climax or conflict, instead constantly vibrating and negotiating in the middle through continued change. It is important here to note that Bateson recognizes that schismogenesis is not absent in Balinese society: occasionally the plateau is disrupted and some sort of crisis emerges. Balinese society is thus not romanticized as violence-free, or as a model for an ideal system. Similarly, plateaus in Deleuze and Guattari are not perfect, are not free from topographies of power: "there are knots of arborescence in rhizomes, and rhizomatic offshoots in roots" (Deleuze \& Guattari, 1987:22). As such the plateau and the rhizome are not perfect answers, but ways of being which are always open to multiplicity and the becoming of the world.

So for Deleuze and Guattari, the aim of $A$ Thousand Plateaus is to create rhizomatic plateaus of intensity which can offer new vocabularies for overcoming the 'schismogenic' sequences of psychology and capitalism. Rather than the concept of schismogenesis, Deleuze and Guattari identify trends of territorialization and deterritorialization in all relationships. In their vocabulary, 'lines of flight' (or potentially 'lines of absolution) are practices or activities which result in the plateau losing sufficient cohesion - a process of 'deterritorialization' - which can result in the collapse of the plateau (Deleuze and Guattari, 1987). Neither Bateson nor Deleuze and Guattari claim that a plateau which never experiences violence can be created. However, Deleuze and Guattari's vocabulary of lines of flight is clearer that there is a constant task of maintaining the plateau against trends that would destroy it. In Volume One, Anti-Oedipus, they identify that the strongest lines of flight are created by the Oedipal process of the 'double bind' (G. Bateson, 1973:379). This, we are told, is "Oedipalizing par excellence" (Deleuze \& Guattari, 1983:79), and is the form of 'schismogenesis' faced by the schizophrenic. The double bind consists of two injunctions which are submitted simultaneously and which contradict each other: "for example, the father who says to his son: go ahead, criticize me, but strongly hints that all effective criticism... will be very unwelcome" (Deleuze \& Guattari, 1983:88). For Bateson, the double bind is a 'schizophrenizing' situation, which creates a confusion between different 'logical types', that is, between the information communicated through semiotics ('criticize me') and that communicated through actions or metacommunication ('criticism 
is unwelcome'). What is crucial about this for Bateson is that it is an everyday occurrence which does not inherently lead towards schizophrenia. Rather, the double bind is "an experiential component in the determination or etiology of schizophrenic systems and related behavioural patterns" (G. Bateson, 1973:272). The double bind generates some sort of conflict between logical types: it is this conflict which begins schismogenic sequences.

For Bateson, a schizophrenic episode is just one of a series of possible responses to the double bind, and he becomes interested in how alternative response might be curated. These other responses may be very positive: "if this pathology can be warded off or resisted, the total experience [of the double bind] may promote creativity" (G. Bateson, 1973:278). Bateson suggests forms of therapy which encourage responses to the double bind that are creative, whether through play, art or other means: as Deleuze and Guattari say, "a schizophrenic out for a walk is a better than a neurotic lying on an analyst's couch" (Deleuze \& Guattari, 1983:2). For Deleuze and Guattari, however, the double bind is more than a cause of schizophrenia. For them, it is "a common situation ... the double bind is none other than the whole of Oedipus" (Deleuze \& Guattari, 1983:88). Oedipus is thus a series, an oscillation between two poles or planes, of normality and neurosis or structure and crisis, each of which is equally impossible. This is the opposite of the plateau of intensity: a response to schismogenesis which involves a violent resolution. The answer to the problem of Oedipus is not, therefore, to solve it - it is unsolvable - but rather to "do away with both the problem and the solution" (Deleuze \& Guattari, 1983:90), to think of ways in which life can be lived without struggling between structure and crisis, or normality and neurosis. Through the plateau of intensity, the drive towards the poles of structure and crisis is removed. It is the diagnosis of this problem in volume 1 , and attempts to set out new plateaus as solutions in volume 2, which ties together Capitalism and Schizophrenia.

Beyond the earthly concepts of rhizome and plateau, there are further influences from Bateson to Deleuze and Guattari which are worth briefly mentioning. It seems likely that the concepts of 
assemblage and the machinic owe something to Bateson's own work on systems and feedback: at least, both ideas attempt to explore the same problems as Bateson, and come up with remarkably similar solutions. Venn claims that Bateson's work on adaptation and the notions of open and closed systems that are developed in cybernetics are influential to the development of assemblage (Venn, 2006). Nonetheless, there is a large jump from the flexibility and fluidity of assemblages in Deleuze and Guattari, and the information-centered systems of Bateson (Guattari, 2000). Bateson's cybernetics is an attempt to understand, map and mathematically represent the relationship between stasis and change; Deleuze and Guattari offer a different, philosophically based method of trying to explore this relationship between difference and change. Chesters and Welsh thus characterize both Bateson and Deleuze and Guattari thinkers of "the subject and social action and their relation to a planetary action system" (Graeme Chesters \& Welsh, 2005:18). Bateson in particular is their beginning point on the 'minor literature' of authors who move towards the work of Deleuze and Guattari and who have focused on the society-subject-nature relationship by looking at complexity, due to his recognition of "the protracted dialogical and cultural nature of a process that is not limited to clearly defined rational increments or linguistic acts of communication"(Graeme Chesters \& Welsh, 2005:199).

Returning to the quote which opened this article, then, we can see a frustration in Deleuze and Guattari with Bateson's failure to deliver the promise of his project: despite his 'deterritorialised' theorization and experimental approach to writing and research, Bateson always allowed his work to be reterritorialised by the dual machines of war and academia (Deleuze \& Guattari, 1987:257). The lack of references to Bateson and the dismissal of "une carrière à l'américaine" suggest this frustration and disappointment. However, in Capitalism and Schizophrenia, Deleuze and Guattari create their 'monstrous children' from a selection of Bateson's concepts, attempting to rediscover their 'revolutionary potential'. Two of the concepts which travel most strongly, the plateau and the rhizome, form part of Deleuze and Guattari's 'geophilosophy' (Bonta \& Protevi, 2004; Deleuze \& Guattari, 1994). Through these two concepts, it becomes clear that the 'geo-' for Deleuze and 
Guattari is in part a way of tying down lines of flight: of creating new 'self-vibrating regions' within which there is sufficient cohesion to avoid lines of flight turning into lines of absolution (that is, what Bateson terms schismogenesis), with sufficient flexibility to avoid the dominance of structure. The third major concept that they develop from Bateson is the 'double bind', which Deleuze and Guattari use to emphasize that schizophrenia is a constant, pervasive and unavoidable experience in society.

Taking up these concepts indicates that Bateson was particularly influential in 'earthing' the dispersed subjectivity developed by Deleuze and Guattari. Bateson was not, of course, the only source for this thinking through the earth. Spinoza, Leibniz and Nietzsche all provide ways into understanding the importance of earth and distributed subjectivity. Furthermore, writers such as Grosz have developed an understanding of the relationship between earth and subjectivity from Deleuze and Guattari, without drawing from Bateson (Grosz, 2008). Protevi identifies four 'registers' of the word 'Terre' in in Deleuze and Guattari, three of which he would translate as 'earth': the "virtual plane of consistency on which strata are imposed"; "the 'earth-territory' system... the gathering point, outside of all territories, of 'forces of the earth' for intensive territorial assemblages"; and "the 'new earth', the correlate of absolute deterritorialization" (Protevi, 2013: 43). Bateson's contribution is in the first of these senses of earth, as providing the "virtual plane of consistency" which is a necessary feature for the formation of plateaus, and for the formation of subjectivity. To explore the relationship with these other forms of 'earth' developed in Deleuze and Guattari would be beyond the scope of this paper. Instead in the next section, I will argue that the further development of Bateson's 'earthing' into an ecosophy by Guattari helps indicate how the earth as 'plane of consistency' forms a key part of the ethico-political dimension of Deleuze and Guattari's work.

\section{Ecosophical Subjectivity: Bateson and Guattari}

The previous section has attempted to fill some of the gaps in the existing literature, exploring Bateson's influence on Deleuze and Guattari's work as a whole, and finishing on his contribution to 
their concept of earth. This also begins the process of creating a Batesonian-inflected reading of Deleuze and Guattari, responding to the existing attempts to understand the earth in contemporary social theory (Bonta \& Protevi, 2004; Latour, 2007; Mackay, 2010; Protevi, 2013). In these theories, the 'spatial turn' of postmodernism and poststructuralism (Soja, 1989) is merged with philosophies which place the 'geo-' and the 'eco-' at the centre of their orientation. Of course, Deleuze and Guattari are not the only source of this earthing of theory, but they are one of the major influences in this area: as they state, their "thinking takes place in the relationship of territory and the earth" (Deleuze \& Guattari, 1994:85). While Deleuze and Guattari identify their work as 'geophilosophical', Guattari's later writing shifts this towards the 'ecosophical'. This adds a new dimension to the geophilosophical, in which the focus shifts slightly from the relationship between territory and earth and towards the three-way relationship of life-territory-earth. Guattari describes the solution as a series of "ecosophic cartographies" (Guattari, 1996a:271): like the plateaus of his previous work with Deleuze, these cartographies contain uncertainty, heterogeneity and diversity. However, developed in conversation with the work of Bateson, they contain a new "ethico-political articulation" in which the very "ways of living on the planet are in question" (Guattari, 2000:19-20).

While emergent in the work of both Deleuze and Guattari, this ecosophy is found in most depth in the work of Guattari specifically, particularly his later writings - that is, in his work that was published after A Thousand Plateaus (Guattari, 1993, 1996b, 2000). The basis for the ethical dimension of Guattari's movement into ecosophy is the grounding of a distributed subjectivity (Guattari, 2000). This subjectivity is built in part out of Bateson's similar move in locating the subject in the relationship between mind and environment: ' $I$ ', as a bounded unit, is for Bateson an epistemological fallacy (G. Bateson, 1973). Repeating the situation described previously, the influence of Bateson on the ecosophy of Guattari is only usually given a brief mention (eg Thrift, 1999). The exploration of Bateson's work in a geographical context tends to be fairly shallow: in The Dictionary of Human Geography, for example, his only mention is under the entry for 'adaptation' (Watts, 2000). Yet Bateson should be considered a major influence for those geographers and 
theorists who have developed Deleuze and Guattari's ideas about dispersed subjectivity, and who have explored the 'earthliness' of Deleuze and Guattari (Malins, 2004; Thrift, 2008; Wylie, 2010). In this section, I want to explore in more detail Bateson's concept of self and mind, and its influence on the transversal concept of subjectivity which permeates through Guattari's work but which becomes more and more apparent in his later writings. In particular, reading Guattari's work alongside Bateson can first bring deeper understanding of Guattari's move towards what he labeled ecosophy, ${ }^{1}$ and can secondly explore the inherently earthly side of Guattari's thought.

Bateson does not frequently use the term subject directly, but does theorize the emergence of mind. He defines mind as "an aggregate of interacting parts or components" (G. Bateson, 1979:92) which is immanent to a system. It emerges from the communication of information across systems: who or what is causing this communication is not, for Bateson, important in defining mind. As such, he is happy to apply this definition of mind to practices of information processing that take place outside of the body. The concept of a bounded mind in the human, or even the notion that 'mind' is solely a human feature, is thus flawed (Bateson, 1973:491). This position is developed out of the classic geophilosophical statement that "the map is not the territory" (Bateson, 1973:180), that is, there is a distinction between the mode of representation (the map) and the object-in-the-world (the territory). Rather than understanding this as a critique of representation, that is, as a failure of representations to fully capture the reality of lived experience, he instead sees this relationship as inherent to all forms of interaction between objects. The map is not intended to refer to manmade representations of territory; rather, it refers to all manifestations of objects as they appear to others, to all experiential objects. Objects, as we experience them, are never full representations of an object-in-the-world, just as maps are never full representations of territories. Rather, 'maps' only contain certain aspects of 'territories'. Specifically, maps represent a series of differences in territory which help identify the distinction between one place and another. These differences pass from the territory into the retina of an observer, along neural pathways, into bodily organs and so on. As such, 
"what you find is an infinite regress, an infinite series of maps. The territory never gets in at all... all 'phenomena' are literally 'appearances'” (460-461).

In any system where objects perceive information about each other, there exist some of the rudimentary features of mind. In other words, Bateson equates mind with this ability to perceive difference, between an infinite regress of objects. Mind emerges not out direct perception of the 'ding-an-sich', but out of the flow of difference across this system of perception. Hence, all minds emerge immanently from systems in which there are flows of difference. Subjectivity, or the emergence of the self, is one particular perception of a system which occurs in this immanent mind of the system. This mind recognises that the system, as a whole, has acted on the world, and therefore ascribes this action to the conscious work of the body. It thus labels itself as 'subject'. The subject cannot, therefore, be said to exist solely within a body. Rather, it is a reification of the mind which is "immanent to the larger system - man [sic] plus environment" (G. Bateson, 1973:317). Bateson provides the example of a man chopping a tree with an axe. The chopping is achieved by the flow of difference across the system - which we might simplify as "tree-eye-brain-musclesstroke-axe-tree" (Bateson, 1973:317). The mind which is immanent to the system identifies that the system has achieved an effect in the world - the chopping - and so attributes this effect to a 'thing', that is, the self or subjectivity: "the average Occidental sees the event sequence of tree felling ... [and] believes that there is a delimited agent, the 'self', which performed a delimited 'purposive' action upon a delimited object" (Bateson, 1973:318). In fact, nothing of the sort has happened. Rather, there has been a machine which in unison has functioned thanks to its immanent mind. Subjectivity thus emerges, for Bateson, as a result of the erroneous epistemologies which identify one's own action as that of a one.

Bateson notes that this 'pathological' epistemology extends to the relationship between the psychiatrist and the patient and then on to other forms of the exercise of power (Bateson, 1973:494). In the psychiatrist's office, both patient and psychoanalyst make the mistake of 
presuming a conversation between two bounded subjects; this, for Bateson, is incorrect. Guattari agrees. He developed the concept of 'transversality' to explore the way in which the setting of psychiatry, and the various bodies in a psychiatric space, together share themselves as part of a collective experience of subjectification (Genosko, 2000). Like Bateson, Guattari used the psychiatrist's office as a metaphor and example for a wider discussion of subjectification. In Chaosmosis, Guattari sets out the three 'problems' which for him prompt this move: "the irruption of subjective factors at the forefront of current events, the massive development of machinic productions of subjectivity and, finally, the recent prominence of ethological and ecological perspectives on human subjectivity" (Guattari, 1995:2). Subjectivity is thus emergent, or produced, from a wide variety of 'machines' of various forms; these machines all have "a certain cartography", that is, they are inherently geographic.

The emergence of this vision of subjectivity which comes from Guattari comes alongside a rejection of other understandings of models of the unconscious - most notably those associated with Freud and psychoanalysis - which see external behaviour as manifestations or representations of a structuring subconscious realm. Guattari instead favours explanations which explore the external objects involved in the emergence of subjectivity. Here, Guattari searches for a 'schizoanalytic' unconscious, which "involves the most diverse material fluxes and social systems" and which "is not the unconscious of specialists, but a region everyone can have access to" (Guattari, 2009:197). As stated above, institutional psychiatry does not take place in a neutral space in which unproblematic transference can occur between analyst and patient, but rather in a range of interconnected and complex sites all of which contribute towards subjectivity (Genosko, 2000). Fundamentally, "the questions raised by psychology no longer fall squarely within the realm of psychology" (Guattari, 2009:197). There are instead a number of social components, both human and non-human, material and institutional, which contribute towards dispersed unconsciousness and thus subjectivity. Guattari spent much of his career working La Borde, a radical clinic which sought to put some of 
these concepts into action in the treatment of psychotic patients. From his work here on the unconscious, he concluded that:

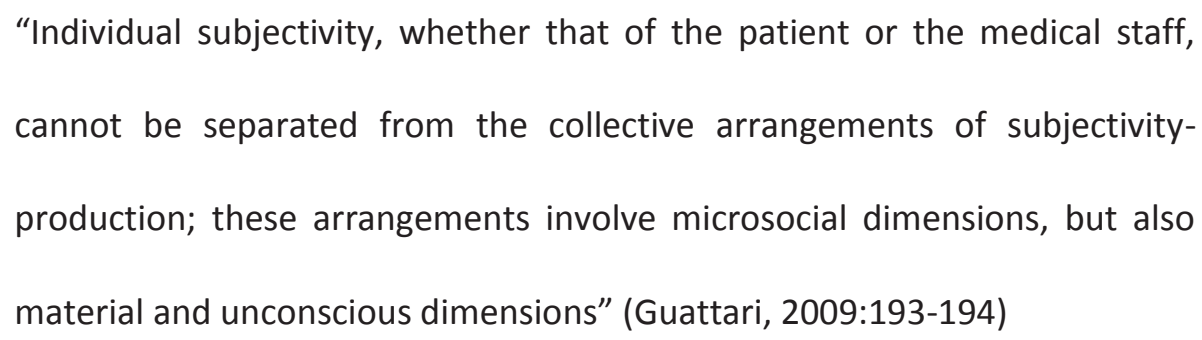

Thus for both Bateson and Guattari, the pathological epistemology to be destroyed was that of a subject separated from environment and/or society. Rather, subjectivity emerges or is immanent, from the transversal experiences of the world.

While building upon previous work both solo and co-authored, three of Guattari's final publications see him move beyond the dispersed subjectivity that he had previously developed, towards a new ecosophical subjectivity. In The Three Ecologies, published in French in 1989 (Guattari, 2000); Space and Corporeity, a presentation given in English in 1991 and published in 1993 (Guattari, 1993); and Chaosmosis, published in French in 1992 (Guattari, 1995), Guattari builds upon the geophilosophical project that he has previously worked on with Deleuze, using Bateson's understanding of the subject to contribute to what he describes as a new emergent ethico-political dimension to his work.

Guattari characterises three dominant forms of ecology: the environment, social relations, and human subjectivity. The broader ecology of the Earth is a result of the interaction between these three ecologies (Guattari, 2000). Writing in 1989, Guattari recognises that what is called 'the ecological crisis' is not just a crisis of the environment, but also of both individual and collective human life. In an ecosophical approach to subjectivity, it behoves us to think not of subject, or even of subject and environment together, but of dispersed vectors or "components of subjectification". In explaining this, Guattari states that 
"Vectors of subjectification do not necessarily pass through the individual, which in reality appears to be something like a 'terminal' for processes that involve human groups, socio-economic ensembles, data-processing machines etc. Therefore, interiority establishes itself at the crossroads of multiple components, each relatively autonomous in relation to the other and, if need be, in open conflict" (Guattari, 2000:25)

Here, Guattari firmly establishes the form of subjectivity which has been developing through the rest of his writings. Guattari's move re-articulates Bateson's separation of subjectivity and the individual, but in a way which recognises that subjectivity involves more than just 'data-processing machines', that is, the flow of information. Rather, a series of other flows - affect, signification, materiality, intensity and desire - all take on a role in subjectification. These establish interiority in specific individuals, but this interiority is always temporary and contradictory. Subjectivity then appears as the final stage in the interaction of these various flows.

By locating the emergence of subjectivity in the environment, social institutions, landscapes and internal fantasies (Guattari, 2000), Guattari joins Bateson in connecting emergent ecological crisis to the crises of subjectivity and society in late capitalism. In other words: "It is the relationship between subjectivity and its exteriority - be it social, animal, vegetable or cosmic - that is compromised" (Guattari, 2000:19). Environmental pollution, the "gangrene of mass-consumption" and the reduction in the strength of personal connections are all identified as being symptoms of this same problem: the 'epistemological fallacy' (G. Bateson, 1973) of the bounded subject and the negative relationships that emerge from this. From Bateson and Guattari, the emergence of these problems lie in ecologies of 'bad ideas', that is in our epistemology of the self, rather than in harmful technological processes (G. Bateson, 1973; Guattari, 2000). As Bateson says, new forms of understanding of the relationships between people and between people and their environment are necessary for the solving of ecological problems, although "nobody can predict what new patterns 
will emerge from these drastic changes" (G. Bateson, 1973:501). Similarly, Guattari offers us a way out of ecological crisis only with changes in all three ecologies, of subjectivity, 'socius' and environment (Guattari, 2000:45). Chesters and Welsh develop these ideas further, looking to new "peasant, socialist, anarchist, feminist, radical liberal and environmental sensibilities" which are "far removed from the dangerous "habits of mind' identified by Bateson" (Chesters and Welsh, 2006:147). For them, the Bateson-Guattari ecosophical approach is shown to offer ways of articulating how the multitude might operate within a globalising world.

The relationship between subjectivity and earth in Guattari thus moves beyond the 'grounding' role that it takes in his work with Deleuze. Through further engagement with Bateson, Guattari builds this role into an ethico-political ecosophical relationship between multiple different ecologies. In Space and Corporeity, Guattari develops further his understanding of subjectivity and earth, with a focus on how these interact through the movement of the body. Bateson overlooks the body somewhat, where it appears most commonly as a tool for information transference. In Guattari, it is much more. He begins with the claim that "the phenomenological approach to space and the lived body reveals the two to be inseparable" (Guattari, 1993:139). Guattari focuses, in greater detail than elsewhere, on experiencing the relationship between environment and subjectivity that he and Bateson theorize. To experience the city is to experience "the span of developed/constructed spaces [which] extend quite beyond their visible and functional structures. They are essentially machines, machines of meaning, of sensation, abstract machines... that carry incorporeal universes that are not universals but that can standardize individual and collective subjectivity" (Guattari, 1993:143-144). One individual may experience dramatic affects in a city that another will not - Guattari relates an experience of dizziness and fear on a Sao Paolo bridge, in which a long-ago perception of great height briefly returns to his body, causing a 'doubling' of perception of space. The built environment and body, then, have operated mechanically, producing a moment of excessive affect in Guattari, which causes this brief experience but which soon passes. Crucially, however, whilst such experiences are neither new nor unique to either the urban or the contemporary, they are increased 
and intensified by hyper-capitalism and complex urban spaces. Guattari sets out a challenge to social scientists working on the city to recognise the constantly fluctuating co-production of Earth and subjectivity, and to respond to this 'polyphonic' subjectivity.

\section{Conclusion}

While the practice of exploring the works which influence Deleuze and Guattari might seem initially to be a rather niche academic exercise, the ideas of Bateson can help expand upon the ethicopolitical dimensions of their theorizations of subjectivity and earth. In light of a proliferation of calls to explore this relationship from a variety of positions in philosophy, social sciences and science (Latour, 2007; Protevi, 2013; Sloterdijk, 2009; Zalasiewicz et al., 2011), this seems a pressing area for research. Bateson's work casts new light on the ideas of Deleuze and Guattari, specifically the Capitalism and Schizophrenia project and the ecosophical subjectivity of Guattari. By exploring how this work developed from a geophilosophy into Guattari's ecosophy, it adds to the relatively tiny literature which currently focuses on this relationship. This absence of work has come despite the clear use of Batesonian terms both in Deleuze and Guattari's Capitalism and Schizophrenia, and in the single-authored work of Felix Guattari. While this relationship is not regularly acknowledged by Deleuze and Guattari themselves, their criticism of Bateson (Deleuze \& Guattari, 1983:257) indicates that this lack of acknowledgement does not reflect a lack of engagement. Rather, Deleuze and Guattari reject Bateson because he comes so close to developing a revolutionary academic project, before being reabsorbed into the state-war machine. There are, of course, further ways in which Deleuze and Guattari differentiate themselves from Bateson. Guattari rejects Bateson's description of action and enunciation as 'context': rather, all the components of an ecology are "heterogeneous elements that take on a mutual consistency" (Guattari, 2000:36). Bateson's description of and understanding of 'systems' also remains much more structured than Deleuze and Guattari: there is no equivalent term to 'assemblage' to be found in Bateson. Bateson's use of Russell and Deleuze's adaptation of Bergson, two philosophers who had fundamental disagreements (Russell, 1912), is 
also indicative of the differences in their philosophical backgrounds. What connects the work of Bateson and Deleuze and Guattari is not a shared philosophical school or approach to research, but as discussed in this article, a shared concern with how we might prevent the emergence of conflict and the connections between social and psychological processes.

Deleuze and Guattari's work in Capitalism and Schizophrenia builds up a vision of the plateau which requires the earth to give it a consistency. Through further engagement with the work of Bateson, Guattari explores how a failure to recognize that subjectivity emerges from its relationship with the earth threatens both earth and subjectivity, and as such the possibility of the creation of plateaus. For Deleuze and Guattari, the subject is 'geographical', in a variety of senses. From Bateson, they draw in particular from the sense of the earth, or the 'geo-', in geography. Whilst the subject in Deleuze and Guattari is always spatial, the imagination of spatially dispersed subjectivities can also be found in, for example, the work of Foucault, in which spaces and subjectivities are constructed together and dispersed. Thus, the "topological localizability" (Saldanha, 2010:290) of both body and subjectivity is drawn into question. Through their and particularly Guattari's engagement with Bateson, they build up a new recognition of the relationship between earth and subjectivity. This emerges as an attempt to counter the increasingly precarious relationship between human, social and environmental ecologies. Subjectivities are scattered across these ecologies, and can only be understood through their spatiality. If the relationships between these ecologies are damaged, then the very being of subjectivity is under threat. As such this is more than a geophilosophy: it is an ecosophy, which brings an ethico-political orientation of responsibility towards the earthed and worldly subjectivity. In other words, because subjectivity and life can only ever be in touch with the 'geo-', an ethical requirement to create new ways of living ecosophically emerges.

\section{Acknowledgements}

This paper has emerged out of work over several years. Thanks to Paul Harrison, Gordon MacLeod, Ben Anderson and Gerry Aiken, who have all looked at various versions of this paper, as well as to 
the suggestions of the anonymous referees and editors. Thanks also to Paul Simpson and James Ash for organising the Geography and Post-phenomenology session at the 2012 RGS-IBG Conference, at which some of the arguments in this paper were presented. Any errors remain the author's own.

\section{Notes}

${ }^{1}$ It is worth noting that Guattari's coining of 'ecosophy' seems to have happened almost simultaneously with but separately from that of Arne Naess (Hampson, 2010; Naess, 1989)

\section{References}

Bateson, G. (1951). 'Information and Codification', pp. 168-211 in J. Reusch \& G. Bateson (eds), Communication: The Social Matrix of Pyschology. New York: W.W. Thomas.

Bateson, G. (1958). Naven. Stanford: Stanford University Press.

Bateson, G. (1968). 'Conventions of Communication', pp. 212-227 in G. Bateson \& J. Reusch (eds), Communication: The Social Matrix of Psychiatry. New York: W.W. Norton.

Bateson, G. (1973). Steps to an Ecology of Mind. St Albans, Australia: Paladin.

Bateson, G. (1979). Mind and Nature: A Necessary Unity. New York: EP Dutton.

Bateson, G., \& Bateson, M. C. (1987). Angels Fear : Towards an Epistemology of the Sacred. New York: Macmillan.

Bateson, G., \& Mead, M. (1942). Balinese character, a photographic analysis. New York: The New York academy of sciences.

Bateson, M. C. (1999). 'New Foreward to Steps to an Ecology of Mind', pp. vii-xv in G. Bateson (ed), Steps to an Ecology of Mind. Chicago: Univeristy of Chicago Press.

Bell, J. A. (2006). Philosophy at the Edge of Chaos: Gilles Deleuze and the Philosophy of Difference. Toronto: Unviersity of Toronto Press.

Bonta, M., \& Protevi, J. (2004). Deleuze and Geophilosophy : A Guide and Glossary Edinburgh Unviersity Press: Edinburgh. 
Chesters, G., \& Welsh, I. (2005). 'Complexity and Social Movement(s): Process and Emergence in Planetary Action Systems', Theory, Culture and Society, 22(5), 187-211.

Chesters, G., \& Welsh, I. (2006). Complexity and Social Movements. Abingdon: Routledge.

Clark, N. (2013). 400ppm: Regime Change in Geo-Social Formations (Vol. 2013). Society and Space Blog: Enivronment and Society D.

Deleuze, G. (1973). 'I Have Nothing to Admit', Semiotext(e), 2(3), 111-116.

Deleuze, G., \& Guattari, F. (1983). Anti-Oedipus : Capitalism and Schizophrenia. Minneapolis: University of Minnesota Press.

Deleuze, G., \& Guattari, F. (1984). 'Concrete Rules and Abstract Machines', SubStance, 3/4, 7-19.

Deleuze, G., \& Guattari, F. (1987). A Thousand Plateaus : Capitalism and Schizophrenia. Minneapolis: University of Minnesota Press.

Deleuze, G., \& Guattari, F. (1994). What is Philosophy. London: Verso.

Genosko, G. (2000). 'The Life and Work of Felix Guattari: From Transversality to Ecosophy', pp. 46-78 in F. Guattari (ed), The Three Ecologies. London: Continuum.

Goodburn, J. (2010). 'Gregory Bateson's Ecological Aesthetics - an addendum to Urban Political Ecology', Ecology, 4(1), 35-48.

Grosz, E. (2008). Chaos, Territory, Art. New York: Columbia University Press.

Guattari, F. (1993). 'Space and Corporeity', Columbia Documents of Architecture and Theory, 2, 139149.

Guattari, F. (1995). Chaosmosis:An Ethico-Aestethtic Paradigm. Sydney: Powet.

Guattari, F. (1996a). 'Remaking Social Practices', pp. 262-272 in G. Genosko (ed), The Guattari Reader. Oxford: Blackwell.

Guattari, F. (1996b). 'Subjectivities: for Better and for Worse', pp. 193-203 in G. Genosko (ed), The Guattari Reader. Oxford: Blackwell.

Guattari, F. (1998). 'Schizoanalysis', The Yale Journal of Criticism, 11(2), 433-439.

Guattari, F. (2000). The Three Ecologies. London ; New Brunswick, N.J.: Athlone Press. 
Guattari, F. (2009). Chaosophy: Texts and Interviews 1972-1977. Los Angeles: Semiotext(e).

Hampson, G. P. (2010). 'Facilitating Eco-Logical Futures through Postformal Poetic Ecosophy', Futures, 42(10), 1064-1072.

Latour, B. (2007). A Plea for Earthly Sciences (Vol. 2009): bruno-latour.fr.

Lipset, D. (1980). Gregory Bateson: The Legacy of a Scientist. Englewood Cliffs, NJ: Prentice-Hall.

Mackay, R. (2010). 'Geophilosophy: Editorial Introduction', Collapse, 6(1), 3-19.

Malins, P. (2004). 'Machinic Assemblages: Deleuze, Guattari and an Ethico-Aesthetics of Drug Use', Janus Head, 7(1), 84-104.

Massumi, B. (1992). A user's guide to Capitalism and schizophrenia : deviations from Deleuze and Guattari. Cambridge, Mass. ; London: MIT.

Naess, A. (1989). Ecology, Community and Lifestyle. Cambridge: Cambridge Unviersity Press.

Protevi, J. (2013). Life, War and Earth. Minnesota: Minnesota University Press.

Rahn, J. (2008). 'Mille Plateaux, You Tarzan: A Musicology of (an. Anthropology of (an Anthropology of A Thousand Plateaus)) [sic]', Perspectives of New Music, 46(2), 81-92.

Russell, B. (1903). The Principles of Mathematics. Cambridge: Cambridge University.

Russell, B. (1912). 'The Philosophies of Bergson', The Monist, 22, 321-347.

Saldanha, A. (2010). 'Politics and Difference', pp. 283-302 in B. Anderson \& P. Harrison (eds), TakingPlace: Non-Representational Theories and Geography. Farnham: Ashgate.

Samuel, G. (2002). 'The Other Side of Rationality: Desire in the Social System', Public Organization Review, 2(4), 415-427.

Schroeder, B. (2012). 'Reterritorializing Subjectivity', Research in Phenomenology, 42(2), 251-266.

Schwartzman, H. B. (1978). Transformations: An anthropology of Children's Play. New York: Plenum Press.

Sloterdijk, P. (2009). 'Geometry in the colossal: the project of metaphysical globalization', Environment and Planning D: Society and Space, 27(1), 39-40. 
Soja, E. (1989). Postmodern Geographies: The Reassertion of Space in Critical Social Theory. London: Verso.

Taffel, S. (2012). 'Escaping Attention: Digital Media, Hardware and Ecological Cost', Culture Machine, 13.

Thrift, N. (1999). 'Steps to an Ecology of Place', pp. 295-323 in D. Massey, J. Allen \& Sarre (eds), Human Geography Today. Cambridge: Polity Press.

Thrift, N. (2008). 'I Just Don't Know What Got into Me: Where is the Subject?', Subjectivity, 22(1), 8289.

Venn, C. (2006). 'A Note on Assemblage', Theory Culture Society, 23(2-3), 107-108.

Watts, M. (2000). 'Adaptation', pp. 6-7 in R. J. Johnston, D. Gregory, G. Pratt \& M. Watts (eds), The Dictionary of Human Geography. Oxford: Blackwell.

Wylie, J. (2010). 'Non-Representational Subjects', pp. 99-115 in B. Anderson \& P. Harrison (eds), Taking-Place: Non-Representational Theories and Geography. Farnham: Routledge. Zalasiewicz, J., Williams, M., Haywood, A., \& Ellis, M. (2011). 'The Anthropocene: a new epoch of geological time?', Philosophical Transactions of the Royal Society A: Mathematical, Physical and Engineering Sciences, 369(1938), 835-841.

\section{Biographical Note}

Robert Shaw is a geographer working as a teaching fellow at Durham University. His major research interests centre on the night and society, as well as exploring theoretical work which attempts to ask how subjectivities are created and managed in urban spaces. He was awarded his PhD in May 2012, and has published his work in Geoforum, Urban Studies and in a chapter in the book Infrastructural Lives, to be published by Routledge EarthScan in 2014. He is currently developing research project ideas including: a study of stag and hen party mobilities in the UK; an exploration of the use of darkness as a design tool in cities; a look at varying experiences of the domestic night. 